\title{
What women (and men) really, really want ...
}

\section{Susan Quilliam}

\section{Contraceptive choice}

When it comes to contraception, of course we family planning professionals know what women want. Take a look at any health information leaflet, or browse through any contraceptive manufacturers' research, and the criteria are clearly defined. Women want effective contraception, safe contraception, protective contraception, reversible contraception. Such issues have informed our work for decades now. You know it makes sense.

Well, it may make sense to us, but apparently it doesn't necessarily make sense to our clients. A recent survey conducted as part of the fpa's 'Contraceptive Awareness Week' campaign in February $2009^{1}$ suggests that for many, contraceptive choice and usage is not nearly so logical and pragmatic as that list I just mentioned. In fact, weight gain, mood swings and lowered desire are apparently the criteria $d u$ jour - all that stuff about safety and protection may be on the list, but it's much further down than we would like to think. Pragmatism is a health professional yardstick and, according to the fpa's findings, is for many women regularly trumped by lifestyle concerns.

\section{Deeper criteria}

All this comes as no surprise to me. The letters I get in my agony columns rarely wax lyrical about a contraceptive method being amazingly safe or eulogise a method because of its added-value STI protection. My readers' key criteria absolutely reflect the fpa's conclusion that women often choose and use their contraception because it fits with feeling fit and looking good. Why? Because those issues are immediate and urgent concerns, whereas the possibilities of getting pregnant or infected are way, way off into an unimaginable and hence ill-considered future.

I'd go further even than the fpa does. I think that many contraceptive criteria are not only much less pragmatic and long-term than has been thought, but also much more conceptual and value-laden. My readers' experience suggests that a huge part of the reason a woman chooses and uses contraception is down to what statement any particular method makes about her and who she is. In short, women are attracted to birth control that makes them feel good about themselves and allows them to give a good impression of themselves to others.

To take a first example, most women want to feel feminine and be seen as feminine; of course they do or why would clothes, makeup and the whole beauty industry play such a huge part in life? But it's that wish for femininity that biases a woman's contraceptive choice against methods that undermine society's definition of beauty and elegance - that tempts her to avoid hormonal contraception because it might pile on the abovementioned pounds, that tempts her to avoid barrier contraception because it involves less-than-graceful insertion and less-thanappetising use of spermicide.

\section{J Fam Plann Reprod Health Care 2009; 35(3): 197-198}

\section{Cambridge, UK}

Susan Quilliam, BA, Cert Ed, MNLP, Freelance Writer, Broadcaster and Agony Aunt

Correspondence to: Ms Susan Quilliam.

E-mail: susan@susanquilliam.com

\section{Self-value trumps pragmatism}

Women in today's society also want to see themselves as uninhibited and passionate - once again that's both obvious and understandable. But if being uninhibited is a key criterion for a woman then she will fight shy of - or, crucially, in the heat of the moment fail to use - methods that create delay, such as the condom and the cap. [In fact there's an important distinction to be made here. It's not so much that women want absolutely instant sex as that they want to be seen to want it - want partners to be impressed by the fact that they are so passionate that they simply can't wait.]

\section{Women are attracted to birth control that makes them feel good about themselves.}

Key too is women's need to be - and to be seen to be lovable and loving; a laudable criterion but one that can equally overrule the pragmatics. Hence if a woman is loving, she considers her partner's desires - so she may stop using the cap or the coil if he complains they ruin his experience. If a woman is lovable, she tries not to make waves - so she may fail to insist on a condom if he asks her to go without "just this once" or "because you love me".

\section{Women in today's society want to see themselves as uninhibited and} passionate.

I'm not saying that the traditional list of contraceptive criteria is inaccurate or irrelevant. What I am saying - as is the fpa - is that if one delves deeper into the reasons behind these criteria one finds additional issues. If one asks "why" a woman uses - or fails to use - a particular method of contraception, one finds a complex web of motivations and demotivations that goes way beyond simple safety or efficacy. Thus when faced with a choice between a less effective method of contraception that leaves a woman feeling feminine, passionate and loving, or a more effective method that leaves her feeling the opposite, she will choose the former. To echo the fpa's conclusions: feeling good trumps pragmatism every time.

\section{Male contraception}

Astute readers may, however, correctly wonder why all the focus in this article so far has been on the female viewpoint. Readers, you are right to challenge, for as a study $^{2}$ in this issue of the Journal highlights - and recent press coverage of the male contraceptive jab has more controversially explored - the division of responsibility for contraceptive protection may well be about to become a very live issue. The time is drawing near when male options will move beyond the starter condom and the laterlife vasectomy to include a whole raft of alternative possibilities.

So what about the lads' criteria? Will they be choosing in terms of effectiveness, safety, protection and reversibility, just as we've always thought women do? Will they be worried about weight gain, mood swings and 
lowered desire, just as we now know women do? Yes, almost certainly some men will consider some of these criteria some of the time. And once again, I believe that men will also choose to use contraception with as much of an eye to self-value judgment as I posit women do.

At present, of course, there's no proof of this. Few studies have been done and certainly none that examine the broader, more conceptual, criteria that I feel need attention. So let me instead - again based on my postbag and my customary Consumer Correspondent psychological slant suggest a few self-value judgments that men might make about contraceptive choosing and using.

\section{A method that leaves a man feeling that he is doing what his mates do will seem} a good idea.

To begin with, a seemingly trivial but - for the younger age group in particular - nonetheless vital criterion: a man needs to have peer approval, to have a self-image as "one of the lads". Hence a method that leaves a man feeling that he is doing what his mates do will seem a good idea: if he believes his mates are using condoms, so will he. If he believes his mates are using hormonal contraception, so will he. (Worryingly, if he believes that his mates are using no contraception at all then, yes, so will he and a recent survey $^{3}$ suggests that if the promised male contraceptive jab ever comes to fruition, $64 \%$ of men who choose to use it will at the same time abandon condom use, making the same peer-supported mistake that so many women have made in not distinguishing contraceptive from infection protection).

\section{Male values}

In older age groups, opposite gender approval becomes more important, and the core need for a man here is to feel not so much that he is approved of by his spouse but that he is responsible for, and looking after, her. Self-value judgment as a 'caring family man' is hugely important to most men at a certain life stage, and it's no coincidence that in the aforementioned study there is a direct correlation between the length and stability of a man's relationship and his willingness to use hormonal contraception.

\section{Any method that leaves a man worrying about future virility problems is likely to get a negative vote.}

Nevertheless, where women want to be connected, men want to be seen to be self-directed. There is a core male self-value judgment about freedom, about not being trapped, about being able to go wherever and do whatever he chooses. No surprise then the study suggests that however much men believe that contraception is an equal function, in practice they are much less willing than women to step up. If taking contraceptive responsibility is seen as too much of a limiter on a man's life, then he is likely to simply step back, revert to the status quo and leave the whole chore to his partner.

Finally, a worrying yet vital criterion: men are even more likely than women to want a self-image as fertile. Absent the physiological commitment involved in pregnancy - and in this day and age absent a shotgun wedding - and men have much less reason to actively avoid conception and every reason to want to know and prove that they are capable of fathering a child. [I'm not speaking about a logical or rational need here; the whole point of this article is to highlight emotional and primal responses to contraception. And when it comes to emotional and primal, every man wants to know he is virile.] Hence any method that leaves a man worrying about future virility problems is likely to get a negative vote; any method that seems easily and provenly reversible is likely to have a good uptake.

\section{And the future?}

Where, then, does that leave us in terms of action? Certainly our original beliefs about women's contraceptive criteria will, as a result of the fpa study, have to shift. Discussion of lifestyle issues will in the end need to take a far bigger role in contraceptive and protective consultations and information giving.

In addition - sexual health decision-makers out there please take note - I would strongly suggest that discussion of self-value judgments also become an integral part of female and male sexual health services. If we can get the message across that a woman can prove her femininity, passion and love - and a man can prove his masculinity, peer acceptability and partnership responsibility - by making good contraceptive choices then I really do believe that contraceptive compliance would rise and contraceptive failure figures would fall.

\section{Discussion of self-value judgments should become an integral part of female and male sexual health services.}

I would equally strongly suggest - pharmaceutical promotion departments out there please take note - that as the new male contraceptives are developed, their introduction to the market includes research into self-value judgment criteria and promotion based on these criteria. We have a huge opportunity, with the introduction of this new raft of possibilities, to set up a new and more effective level of criteria appeals, educating men to make wise choices.

And surely, when it comes down to it, that's what we all - women, men, clients and health professionals - really, really, really want.

\section{Statements on funding and competing interests Funding None identified. \\ Competing interests None identified.}

References

1 fpa. 'Finding the Perfect Partner: Choose What You Use'. Campaign for Contraceptive Awareness Week, 9-15 February 2009. http://www.fpa.org.uk/News/Campaigns/Findingthe perfectpartner [Accessed 3 May 2009].

2 Eberhardt J, van Wersch A, Meikle N. Attitudes towards the male contraceptive pill in men and women in casual and stable sexual relationships. J Fam Plann Reprod Health Care 2009; 35: $161-165$

3 Hall \& Partners. "64\% of men more likely to have unprotected sex on 'male pill"'. 8 May 2009. http://www.sourcewire.com/ releases/rel_display.php?relid=LTmmA [Accessed 8 May 2009]. 